\title{
Cell Invasion Is Affected by Differential Expression of the Urokinase Plasminogen Activator/Urokinase Plasminogen Activator Receptor System in Muscle Satellite Cells from Normal and Dystrophic Patients
}

\author{
Gabriella Fibbi, Emanuela Barletta, Germana Dini, Angela Del Rosso, Marco Pucci, \\ Massimiliano Cerletti, and Mario Del Rosso
}

Department of Experimental Pathology and Oncology (GF, EB, GD, MP, MDR) and Institute of Internal Medicine IV $(A D R)$, University of Florence, Florence, and Divisione Malattie Neuromuscolari (MC), Istituto Nazionale Neurologico "C. Besta," Milan, Italy

SUMMARY: The aim of this study was to evaluate the differential expression and the function in cell movement and proliferation of the urokinase plasminogen activator (u-PA) system in muscle satellite cells (MSC) of normal individuals and patients with Duchenne muscular dystrophy (DMD). By immunoenzymatic, zymographic, and radioligand binding methods and by quantitative polymerase chain reaction of the specific mRNA we have shown that both normal and DMD MSC produce u-PA and the plasminogen activator inhibitor-1 and express u-PA receptors (u-PAR). During the proliferation phase of their growthdifferentiation program, MSC from DMD patients show more u-PAR than their normal counterpart, produce more plasminogen activator inhibitor-1, and release low amounts of u-PA into the culture medium. By Boyden chamber Matrigel invasion assays we have shown that normal MSC are more prone than DMD cells to spontaneous invasion but, when subjected to a chemotactic gradient of u-PA, DMD MSC sense the ligand much better and to a greater extent than normal MSC. u-PA also stimulates proliferation of MSC, but no difference is observable between normal and DMD patients. Antagonization of u-PA/u-PAR interaction with specific anti-u-PA and anti-u-PAR monoclonal antibodies and with antisense oligonucleotides inhibiting u-PAR expression indicates that $\mathrm{u}-\mathrm{PA} / \mathrm{u}-\mathrm{PAR}$ interaction is required in spontaneous and $\mathrm{u}$-PA-induced invasion, as well as in u-PA-induced proliferation. (Lab Invest 2001, 81:27-39).

$M$ uscle satellite cells (MSC) in adult skeletal muscle are mitotically quiescent but can proliferate in response to injury and are thought to be required for the renewal of muscle fiber nuclei, for postnatal fiber elongation, and for regeneration of muscle fibers. When cultured in vitro, these cells proliferate and differentiate into multinuclear myotubes (Campion, 1984; Hartley et al, 1991; Moss and Leblond, 1971; Yablonka-Reuveni et al, 1987). After a proliferative phase, which is characterized by randomly organized cells, myogenic cells align, fuse to form multinucleated cells, and the fusion process is paralleled by a decrease of proliferation rate and formation of myotubes (Mohun, 1992). During myogenesis MSC move within the muscle extracellular matrix (ECM). The process of muscle cell migration and fusion has been suggested to be dependent on extracellular proteolysis (Strittmatter et al, 1982), a feature common to other conditions, such as tumor cell invasion and angiogenesis

Received June 21, 2000.

This study was supported by grants from the Italian TELETHON, Project No. 1074, and Project C.39, and from M.U.R.S.T.

Address reprint requests to: Dr. Mario Del Rosso, Department of Experimental Pathology and Oncology, Florence University, Viale Morgagni, 50, 50134 Florence, Italy. E-mail: DelRosso@unifi.it
(Mignatti and Rifkin, 1993). Two classes of membraneassociated proteases are involved in the degradation of ECM allowing cell migration, the plasminogen activator/plasmin (PL) system and the matrix metalloproteinase system (MMP). The urokinase plasminogen activator (U-PA) interacts with its membrane receptor (u-PAR) and activates the single-chain proenzyme plasminogen (PLG) to the two-chain broad-spectrum serine proteinase $\mathrm{PL}$, which is able to degrade ECM directly or indirectly, through activation of pro-MMP. There is evidence that activation of PLG occurs on cell surface receptors for PLG/PL present in several cell lines (Plow et al, 1986). Also membrane-type matrix metalloproteinase (MT-MMP) undergoes a PLdependent activation that enables the MT-MMP to activate membrane receptor-bound progelatinase $A$ (Vassalli and Pepper, 1994), thus triggering a multienzyme cascade leading to ECM destruction and cell progression. MSC are provided with the components of the cell surface-associated plasminogen activator/PL system, which undergoes modulation during myogenic differentiation in vitro (Quax et al, 1992). It has been suggested that the cell surface plasminogen activation could be required for cell migration, cell division, and cell fusion. Recent data indicate a dual function of cell-associated and soluble u-PA in regu- 
lating cell migration and in controlling cell differentiation, respectively (Wells and Strickland, 1997). Inhibition of u-PA/u-PAR binding, both by monoclonal antibody anti-u-PA or by noncatalytic forms of u-PA, reduces myotube formation (Munoz-Canoves et al, 1997; Quax et al, 1992; Wells and Strickland, 1997). Furthermore, Wang et al (1995) have shown that u-PAR mediates mechanical force transfer across the myoblast cell surface. In the present study, we examined the functions of the urokinase-plasminogen activator system on the membrane of human MSC from normal individuals and patients with Duchenne muscular dystrophy (DMD). Both normal and dystrophic MSC express u-PAR and produce u-PA and the plasminogen activator inhibitor type 1 (PAI-1). MSC from DMD patients express more $\mathrm{u}-\mathrm{PA}$ receptors than their normal counterpart, produce much more PAI-1, and release very low amounts of u-PA during proliferation. In this setting, normal MSC are more prone than DMD MSC to spontaneous invasion of reconstituted basement membrane (Matrigel), which strongly relies on the surface-associated plasminogen activator/ plasmin system. MSC from dystrophic patients display higher chemoinvasion properties under a gradient of U-PA, which is able to elicit chemoinvasion, proliferation, and differentiation of MSC from both sources. The role of $u-P A / u-P A R$ interaction in these processes was assayed by inhibition of surface u-PAR with monoclonal anti-u-PAR antibody and by inhibiting u-PAR expression with antisense oligodeoxyribonucleotide (aODN) against u-PAR mRNA.

\section{Results}

\section{The U-PA/U-PAR/PAI-1 System in Human Normal MSC and DMD MSC During Growth and Differentiation}

The characterization of the u-PA/u-PAR/PAI-1 system of both normal and DMD MSC was performed at various time intervals corresponding to different growth and differentiation phases. Cells $\left(40 \times 10^{3}\right)$ were plated in DMEM with 20\% FCS and cultured as described in "Materials and Methods." Figure 1 shows the typical pattern of proliferation of normal and DMD MSC, allowing identification of four different phases: phase 1, from plating to the 5th day, which indicates active proliferation until cells reach about $70 \%$ confluence (Fig. 1, A and E); phase 2, from the 5th to the 10th day, when cells reach confluence and form a monolayer culture (Fig. 1, B and F); phase 3, from 10 to 14 days after plating, during which MSC line up (Fig. 1, C and $\mathrm{G}$ ); and phase 4, the typical differentiation phase characterized by the presence of differentiated myotubes (Fig. 1, D and H). It noteworthy that MSC from normal patients grow faster than DMD MSC and reach confluence at higher density. From a morphological standpoint, normal cells (Fig. 1, A to D) look very different from DMD myoblasts (Fig. 1, , E to $H$ ). Proliferating MSC from DMD patients have larger, more spread out cytoplasm and an irregular, sometimes stellate morphology. At confluence (Fig. 1, F) they do not form a regular monolayer, but an irregular network with large bundles of cells. After the alignment phase (Fig. 1, G), DMD MSC form few abnormal myotubes, often with a stellate morphology (Fig. 1, H). These morphological characteristics were consistently observed in MSC from each patient examined. In each phase we evaluated total u-PAR and u-PAR distribution between the cell surface and the cytoplasm, u-PA and $\mathrm{PAl}-1$ released into the culture medium, and the affinity of $u-P A / u-P A R$ interaction.

The $u-P A R$. Figure 2A shows the amount of u-PAR in the four phases of MSC growth and differentiation. Proliferating human MSC showed higher levels of u-PAR when compared with confluent and differentiated cells, confirming previous observations on mouse skeletal muscle cell lines (Wells and Strickland, 1997). The pattern was similar for both normal and DMD MSC. Interestingly, DMD MSC express more u-PAR than normal MSC at each time interval, the greater difference being observed in proliferating cells where DMD MSC express about twice as much u-PAR as their normal counterparts. In some cell model systems, u-PAR expression has been related to cell density (Li et al, 1999). Since normal MSC grow faster and reach confluence at higher densities than DMD MSC, we also measured u-PAR as a function of plating density in both cell lines to investigate the possibility that the observed result was not a densityrelated artifact. For this purpose, normal and DMD MSC were plated at $10 \times 10^{3}, 20 \times 10^{3}$, and $40 \times 10^{3}$ cells/dish and u-PAR was determined at the fourth day, during the proliferation phase, by ELISA on aliquots of the cell lysate. No density-dependent differences of U-PAR expression were observed in either normal or DMD MSC. The resulting amount of u-PAR was $2.43 \pm 0.46 \mathrm{ng} / 10^{6}$ cells in normal MSC and 5.72 $\pm 1.12 \mathrm{ng} / 10^{6}$ cells in DMD MSC, independent of the plating density. To check whether there is a differential distribution of u-PAR between the cell surface and the cytoplasm while MSC develop their proliferation/differentiation program, we also measured the ratio between externally and internally located u-PAR. For this purpose, at $5,10,14$, and 28 days, respectively, parallel wells were treated with glycosylphosphatidylinositol-specific phospholipase C (GPIPLC) as described (Del Rosso et al, 1992) to cleave the GPI anchor linking u-PAR to the cell surface. u-PAR determination was then performed on aliquots of the GPI-PLC incubation medium (external u-PAR) and of the cell lysate of GPI-PLC-treated cells (internal u-PAR). About $50 \%$ of total u-PAR was exposed at the external cell surface in all the cell lines from both sources at each time interval after plating (results not shown). Ligand-binding experiments with ${ }^{125} \mathrm{I}-\mathrm{u}-\mathrm{PA}$ were also performed to measure ligand/receptor affinity over the time. MSC were plated in four different 24-well plates for each cell line and binding experiments were performed at the same time intervals described above. The Scatchard analysis of binding data indicated a Kd of u-PA/u-PAR interaction ranging from 0.848 to $0.910 \times 10^{-10} \mathrm{M}$ in both cell lines. These experiments confirmed the decrease of u-PAR num- 

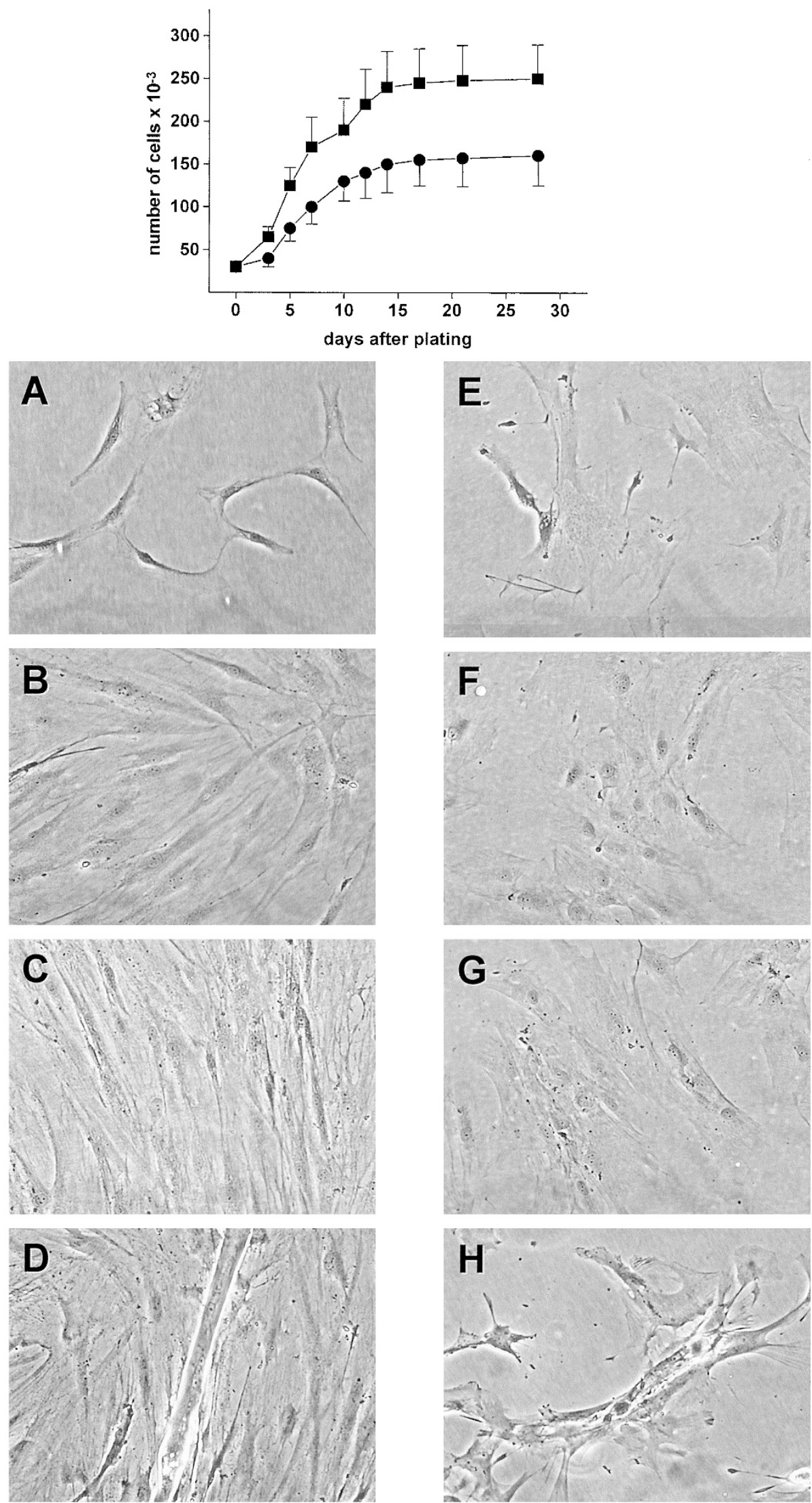

\section{Figure 1.}

Growth profile of normal $(\mathbf{\square})$ and Duchenne muscular dystrophy (DMD) (-) myoblasts. At fixed time intervals after plating (4 days, A and E; 10 days, B and F; 14 days, $\mathrm{C}$ and $\mathrm{G}$; 28 days, D and H), normal muscle satellite cells (MSC) (A to D) and DMD MSC (E to H) were washed with PBS and fixed in methanol overnight. Cells were observed and photographed at $2000 \times$ without staining. 
ber from the proliferation to the differentiation phase and the higher amount of U-PAR in DMD MSC compared with normal MSC (not shown).

$U P A$ and $P A /-1$. Figure $2 B$ shows the densitometric pattern of casein lysis bands obtained by direct zymography of aliquots of the culture medium from normal and DMD MSC at the reported time intervals after plating. While MSC progress from the proliferation to the differentiation phase, soluble u-PA is increasingly detectable in the cell culture medium, either as activity (Fig. 2B) or as antigen (Fig. 2C). The basic level of U-PA activity was slightly higher for normal than for DMD MSC. Whereas the U-PA activity of DMD MSC rose in the last phase, characterized by scarcely differentiated cells, normal MSC reached the peak of released $u-P A$ during the predifferentiation phase, and the activity dramatically dropped during the fusion phase. To evaluate u-PAR-bound u-PA, parallel cul-

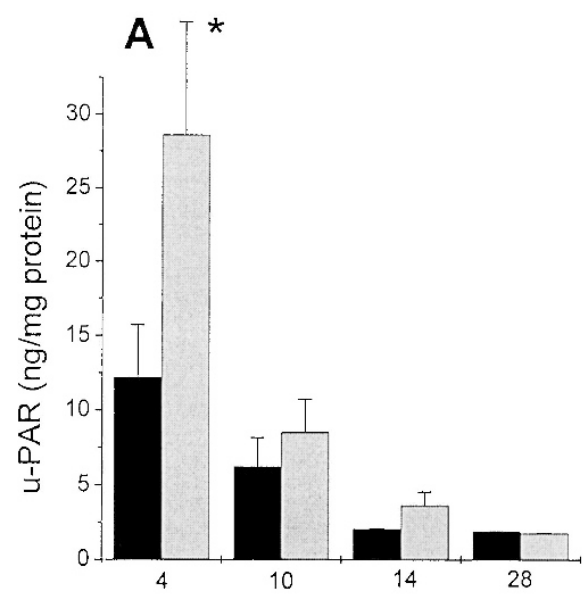

days after plating

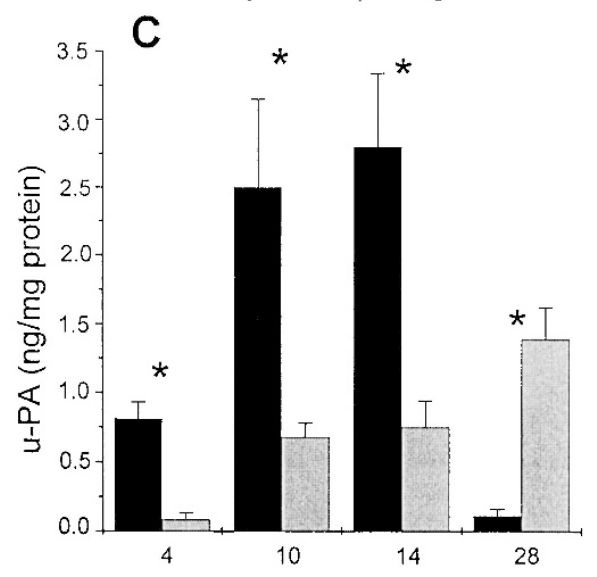

days after plating tures were washed and treated with GPI-PLC, as described above. Such treatment releases $u-P A R$ and u-PAR-bound u-PA, which was measured in the incubation medium at the end of the treatment ( 2 hours). Values of u-PAR-bound u-PA for normal MSC (expressed in $\mathrm{ng} / \mathrm{mg}$ protein) were $0.87 \pm 0.13$ at Day 4 , $1.76 \pm 0.31$ at Day $10,1.57 \pm 0.28$ at Day 14 , and 0.25 \pm 0.06 at Day 28. In the case of DMD MSC, u-PARbound u-PA was undetectable at days 4 and 10. At days 14 and 28 such values were $0.41 \pm 0.1$ and 0.89 \pm 0.15 , respectively, in agreement with the amounts of u-PA secreted into the culture medium. The amounts of secreted PAl-1 inversely mirrored those of u-PA. The basic level of PAl-1 activity was three times higher in DMD than in normal MSC and the difference was maintained while cells progressed toward differentiation, until the PAl-1 became hardly detectable in both conditions (Fig. 2D).

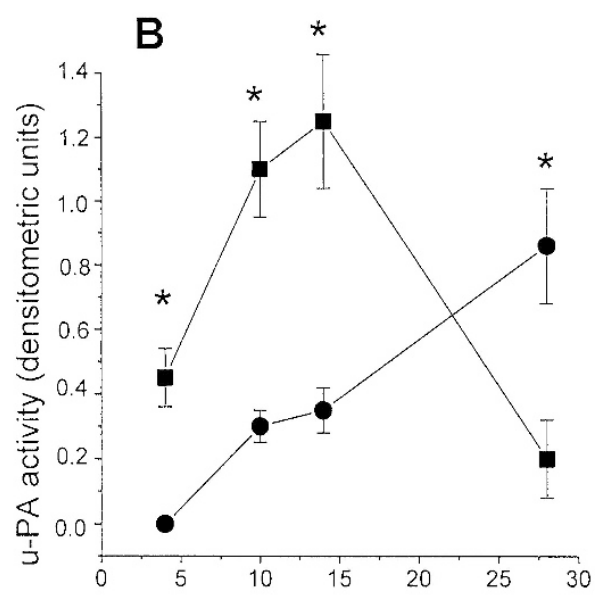

days after plating

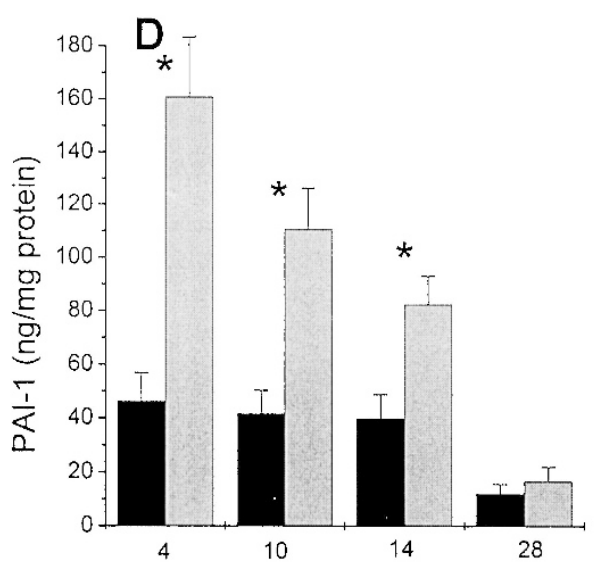

days after plating

Figure 2.

Fibrinolytic pattern of normal and DMD myoblasts. A, Urokinase plasminogen activator receptors (u-PAR) were quantified by ELISA assay on aliquots of cell lysates from normal (black columns) and dystrophic (grey columns) MSC at the time intervals reported in Figure 1. B, $30 \mu$ l of culture medium from normal ( $\square$ ) and DMD (@) MSC were subjected to SDS-polyacrylamide electrophoresis and transferred onto nitrocellulose as described in "Materials and Methods." Urokinase plasminogen activator (u-PA) activity, revealed as clear lysis bands in the cloudy casein background stained with Ponceau S solution as described, was quantified by densitometric scanning, and compared with standard u-PA. C, u-PA antigen was quantified on aliquots of the culture medium by ELISA assay and reported as ng/mg cell protein. Black columns, normal MSC; grey columns, DMD MSC. D, Plasminogen activator inhibitor type 1 (PAl-1) was also measured in aliquots of the culture medium and reported as ng/mg cell protein. Black columns, normal MSC; grey columns, DMD MSC. In all panels, each point represents the mean \pm SD of three experiments performed in triplicate in six normal and six DMD cell lines. ${ }^{*}$ Indicates that values are significantly different from the corresponding value of the normal or DMD counterpart $(p<0.05)$. 
RT-PCR Analysis of the Expression of u-PAR, u-PA, and PAl-1 mRNA. We then addressed the problem of evaluating whether the observed differences of u-PAR, u-PA, and PAl-1 expression between the proliferation and differentiation phase and between normal and DMD MSC were related to differences in the specific mRNA. Figure 3 shows the RT-PCR analysis of u-PA receptor, u-PA, PAl-1, and glyceraldehyde-3phosphate dehydrogenase (GAPDH) mRNA, and Figure 4 shows the quantification by densitometry of PCR amplification products stained with ethidium bromide. The values were normalized to the starting cDNA volumes and referred to the PCR products relative to GAPDH mRNA used as an internal standard as described above. The specific mRNA levels reflected the protein levels regarding the differences both between proliferation and differentiation phases and between normal and DMD MSC in the case of U-PAR. Considering $\mathrm{u}-\mathrm{PA}$ and $\mathrm{PAl}-1$, the differences observed in the proteins between the proliferation and differentiation phases were reflected in specific mRNA in both cell lines. On the other hand, the amount of specific u-PA and PAl-1 mRNA measured in the proliferation phase in normal and DMD myoblasts did not show appreciable differences.

\section{u-PA Determines Matrix Invasion and Proliferation of MSC from Normal and Dystrophic Patients}

During myogenesis MSC move within the surrounding matrix. To mimic this condition, we studied both spontaneous and u-PA-induced invasion of MSC. Figure $5 \mathrm{~A}$ shows that normal and DMD MSC are differentially prone to spontaneous invasion, normal MSC being at least twice as invasive as DMD cells. In experiments with all the normal and DMD MSC lines, invasivity of DMD cells ranged from $20.6 \%$ to $61.7 \%$ with respect to normal MSC. Cells were also challenged with increasing concentrations of $\mathrm{u}$-PA in the lower well of the migration chamber to assay chemoinvasion of Matrigel. Also, in this case a striking difference was reproducibly observed between normal and DMD MSC lines. MSC from normal individuals sensed u-PA weakly at u-PA concentration in the lower well of $100-200 \mathrm{ng} / \mathrm{ml}$. On the other hand, MSC from DMD patients were induced to invasion even under lower u-PA concentrations and the movement always involved a larger percentage of cells (Fig. 5B and inset), in contrast with observations on spontaneous invasion. The amino-terminal fragment of u-PA (ATF), DFP-u-PA, and low molecular weight u-PA were all unable to elicit chemoinvasion. Indeed, ATF and DFP-u-PA showed inhibiting properties when incubated with cells in the upper well of the migration chamber or in the lower well in parallel with u-PA (not shown). These data indicate that chemoinvasion requires the activity of the intact u-PA molecule, including the catalytic site. Subconfluent serum-starved MSC monolayers were exposed to increasing u-PA concentrations (1-1500 ng/ml) for 48 hours and cell numbers were counted at the end of incubation. As shown in Figure 5C, proliferation was stimulated by

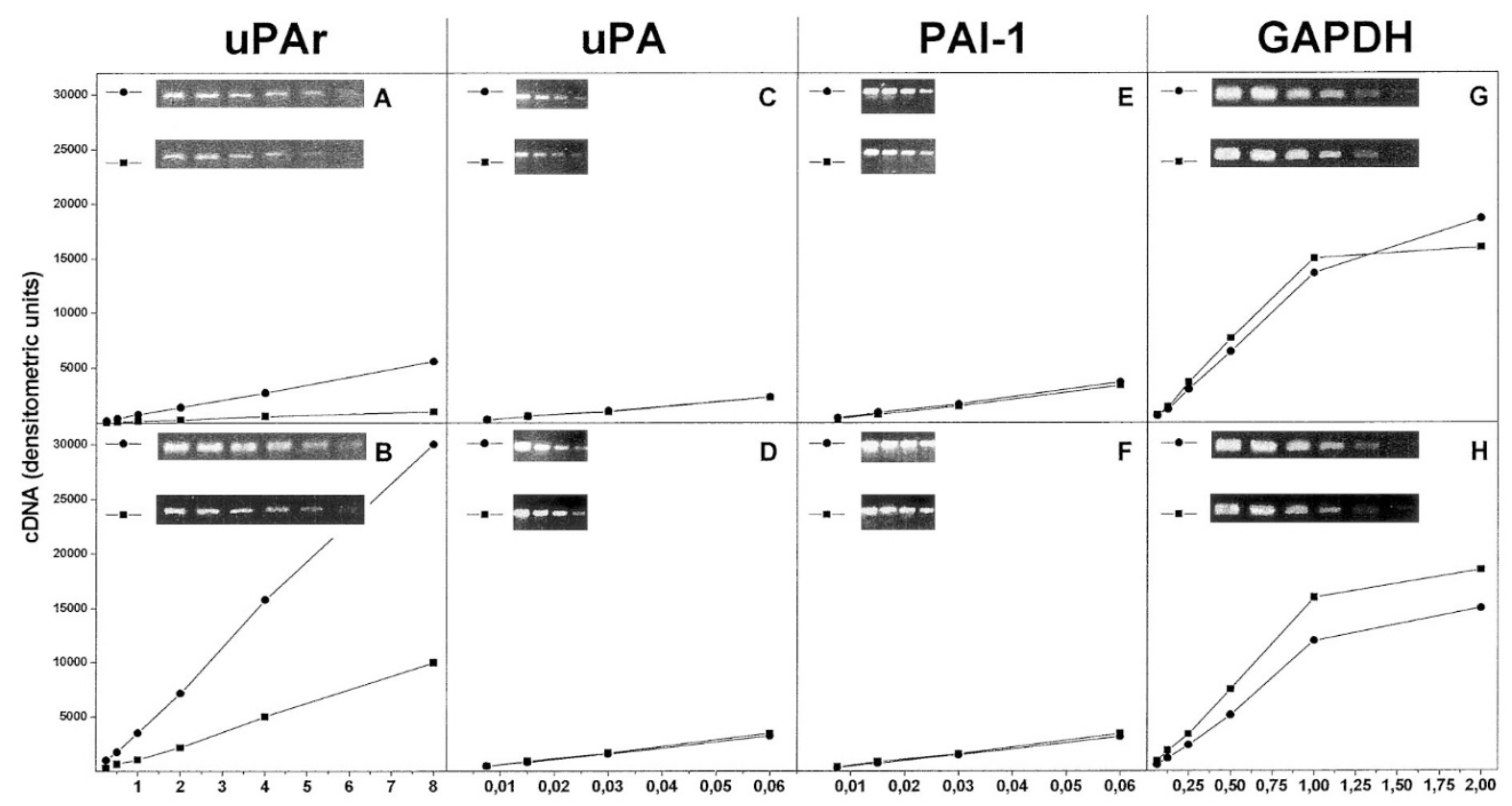

RT products (\%)

Figure 3.

RT-PCR analysis of the expression of u-PAR, u-PA, PAl-1 mRNA, and glyceraldehyde-3-phosphate dehydrogenase (GAPDH) mRNA. For the RT reaction, $1 \mu \mathrm{g}$ of total RNA isolated from undifferentiated $(\bullet)$ and differentiated $(\mathbf{\square})$ normal MSC (A, C, E, G) and from DMD MSC (B, D, F, H). The indicated aliquots of u-PAR, u-PA, PAI-1, and GAPDH retrotranscripts, expressed as percentages of total RT reaction volume, were used in PCR. After 25 cycles of PCR amplification, 10- $\mu$ l aliquots were taken and separated on a $1 \%(\mathrm{w} / \mathrm{v})$ agarose gel containing ethidium bromide $(1 \mu \mathrm{g} / \mathrm{ml})$. The PCR products were quantified densitometrically by a laser scanner as described in "Materials and Methods." Inserts correspond to the ethidium bromide staining of the PCR products. 

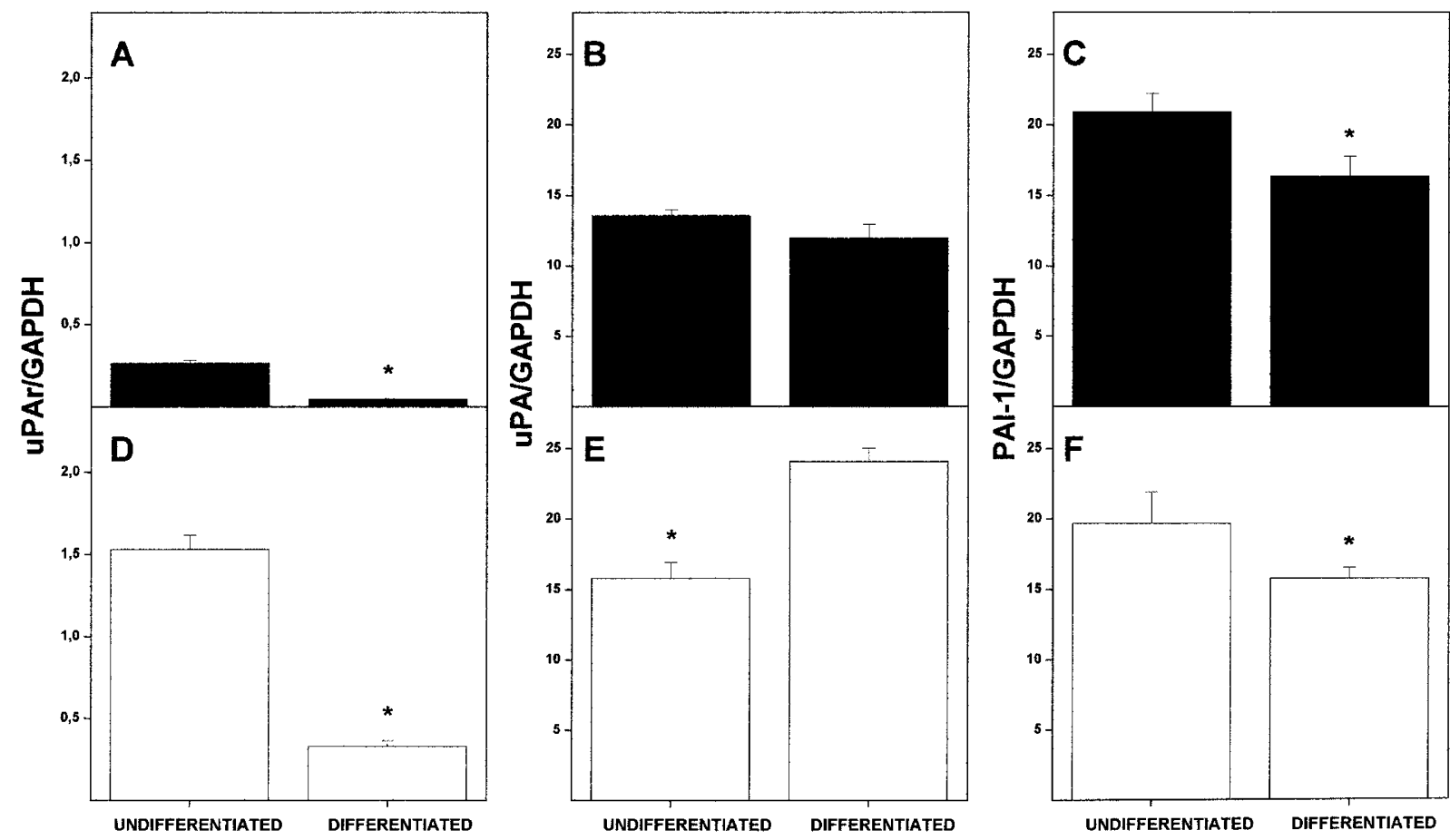

Figure 4.

Levels of u-PAR, u-PA, and PAI-1 mRNA in normal and DMD myoblasts. Three values of u-PAR, u-PA, PAI-I, and GAPDH PCR amplificates, falling within the range of linearity, were normalized to the total starting retrotranscripts volumes. Data are expressed as the ratio of u-PAR, u-PA, and PAl-1 mRNA/GAPDH mRNA in undifferentiated or differentiated normal cells $(A$ to $C$ ) and DMD cells (D to F). Data reported represent the mean $\pm S D$ of three determinations for each point. * At the 0.05 level of Student's $t$ test, the two means are significantly different.
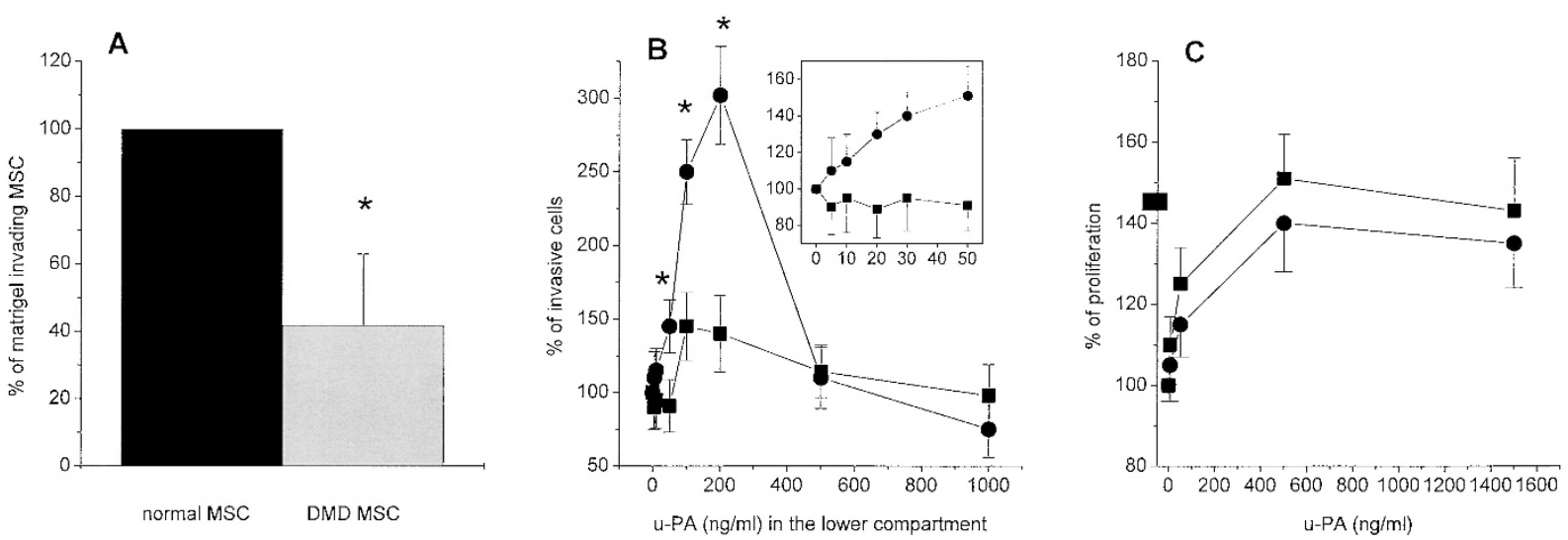

Figure 5.

Spontaneous and u-PA-dependent invasion and u-PA-dependent proliferation in normal and DMD myoblasts. A, Spontaneous invasion of normal (black column) and DMD (grey column) myoblasts. $2.5 \times 10^{4}$ cells were placed in the upper well of a Boyden chamber where the separating membrane was coated with Matrigel and the cells were counted on the lower side of the filter after 6 hours of spontaneous migration. Values are expressed as the percentage of invading DMD MSC with respect to normal MSC (as 100\%) and refer to experiments performed in triplicate on six different lines of normal and DMD myoblasts. B, Chemoinvasion of Matrigel-coated membrane by normal $(\square)$ and $\operatorname{DMD}(\mathbf{O})$ myoblasts. Values of invading cells are expressed as the percentage of invading cells at each chemoattractant concentration with respect to the response of each cell line under basal unstimulated conditions. The inset in B reports the percentage of invasive cells at low $\mathrm{u}-\mathrm{PA}$ concentrations $(5,10,20,30$, and $50 \mathrm{ng} / \mathrm{ml} \mathrm{u}-\mathrm{PA}$ ) (axes labels are the same as in B). Each value represents the mean $\pm \mathrm{SD}$ of three experiments performed in triplicate on three normal and three DMD myoblast lines. C, Proliferative response of normal $(\mathbf{\square})$ and DMD $(\bullet)$ myoblasts 48 hours after challenge with increasing u-PA concentrations, as described in "Materials and Methods." Values refer to the percentage increase in cell number for each cell line with respect to the number of cells at the beginning of $u-P A$ stimulation (as 100\%) and represent the mean \pm SD obtained in experiments performed in triplicate on six normal and six DMD cell lines. The black symbol on the $y$ axis represents the increase in the number of cells of normal MSC stimulated with $10 \mathrm{ng} / \mathrm{ml} \mathrm{b}-\mathrm{FGF}$, taken as positive control. * Indicates that values are significantly different from the corresponding value of the normal or DMD counterpart $(p<0.05)$.

u-PA in a dose-dependent fashion. Although u-PAdependent cell proliferation was observed in both normal and DMD MSC at low u-PA concentrations $(1-10 \mathrm{ng} / \mathrm{ml})$, the plateau was reached between 50 and $500 \mathrm{ng} / \mathrm{ml}$ and proliferation remained high at higher $u$-PA concentrations. u-PA-ATF and DFP-u-PA, as well as low molecular weight-u-PA, were unable to stimulate proliferation. No differences in u-PA-depen- 
dent growth were observed between normal MSC and MSC from DMD patients.

\section{Addition of Exogenous u-PA Stimulates Normal and DMD MSC to Enter the Differentiation Pathway}

Figure 6 shows the effect of exogenous u-PA addition on the differentiation of normal and DMD MSC. These experiments were performed on each one of the normal and DMD cell lines currently used in our laboratory, with similar results. Cells $\left(40 \times 10^{3}\right)$ were plated in DMEM with $20 \%$ FCS in six multiwell plates (3.5 cm diameter per well). Muscle stem cells from both sources were added with $2 \mathrm{ng} / \mathrm{ml}$ u-PA immediately after plating. This concentration was chosen on the basis of the u-PA level measured in normal MSC culture medium at days 10 and 14, corresponding to $1.8 \mathrm{ng} / \mathrm{ml}$ culture medium (in Fig. 2C u-PA is expressed on a per mg cellular protein basis), which represents the predifferentiation u-PA concentration
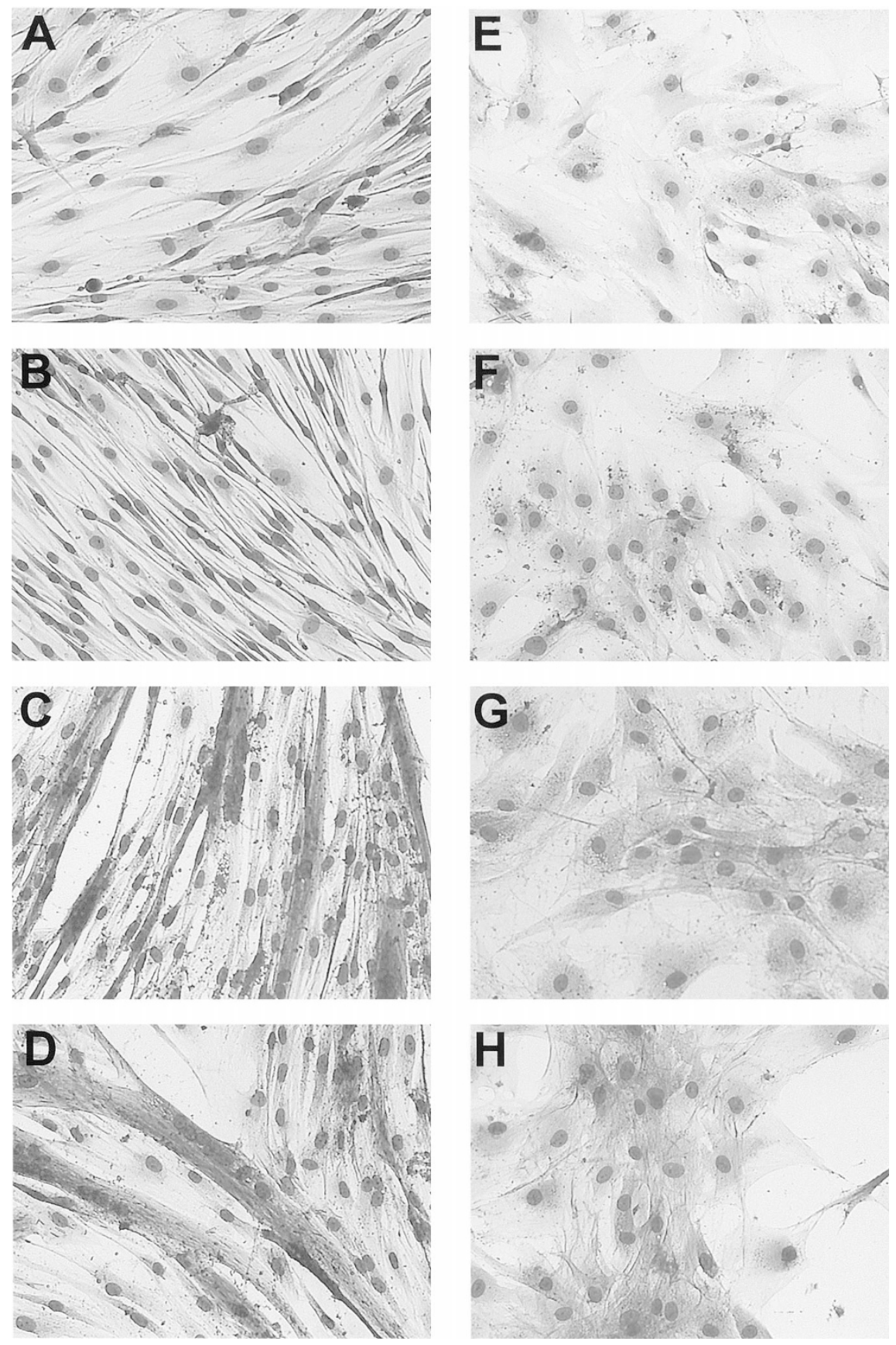

Figure 6.

Differentiation pattern of a representative normal and DMD MSC after addition of exogenous u-PA. Similar results were obtained for each normal and DMD line used in this study. Exogenous u-PA was added immediately after plating $(2 \mathrm{ng} / \mathrm{ml})$ and medium containing fresh u-PA was changed twice a week, as described. At fixed time intervals after plating ( 4 days, $A$ and $E ; 10$ days, $B$ and $F ; 14$ days, $C$ and $G ; 28$ days, $D$ and $H$ ), normal MSC (A to D) and DMD MSC (E to H) were washed with PBS and fixed in methanol overnight. Cells were observed and photographed at 2000× after staining with Diff-Quick. 
required during the normal MSC differentiation program. Culture medium supplemented with $2 \mathrm{ng} / \mathrm{ml}$ u-PA was changed twice a week in both cell lines to maintain cell monolayers under a continuous pressure of u-PA. Figure 6, A to D shows the morphology of normal MSC monolayers at days 5, 10, 14, and 28 after plating in the presence of $2 \mathrm{ng} / \mathrm{ml}$ exogenous u-PA. Figure 6, $\mathrm{E}$ to $\mathrm{H}$ shows the morphology of DMD MSC, cultured under the same conditions, at the same time intervals. When the morphological pattern of each cell line is compared with that of the unstimulated counterpart (Fig. 1), it is evident that the differentiation program in the presence of exogenously added $\mathrm{u}-\mathrm{PA}$ is shortened in both normal and DMD MSC. In fact, at the fifth day of culture, both cell lines showed many foci of confluent cells (Fig. 6, A and E) and the alignment was achieved within Day 10. At Day 14 myotubes were present in normal and DMD MSC and their number showed only a slight increase at Day 28. It is noteworthy that cells from DMD patients formed abnormal myotubes, often with a stellate morphology, even in the presence of exogenous u-PA. ATF, DFP-u-PA, and low molecular weight u-PA were unable to stimulate MSC differentiation, indicating that such a stimulation required the activity of the intact u-PA molecule (not shown).

\section{u-PA/u-PAR Interaction Is Required for Spontaneous Invasion, Chemoinvasion, Growth, and Differentiation in Normal and DMD MSC}

Spontaneous invasion was performed as previously described and chemoinvasion was stimulated with $100 \mathrm{ng} / \mathrm{ml} \mathrm{u}-\mathrm{PA}$ in both normal and DMD MSC. Myotube formation was determined by fixing cells in methanol, staining the cells with Diff-Quick, and quantifying the percentage of nuclei contained within multinucleated myotubes at Day 14, after stimulation of MSC monolayers with exogenous u-PA. To assess the requirement and the specificity of u-PA, a monoclonal antibody that impairs ligand-receptor interaction by masking the u-PA A chain (mAb 5B4) was used (Fibbi et al, 1999). In the differentiation studies, mAb were maintained in the culture medium, together with u-PA, since the beginning of the culture. As shown in Figure $7 \mathrm{~A}$, in the presence of $1.5 \mu \mathrm{g} / \mathrm{ml}$ of $5 \mathrm{~B} 4 \mathrm{mAb}$, spontaneous invasion of both cell lines did not occur, as well as u-PA-dependent chemoinvasion (Fig. 7B). Also u-PA-stimulated cell growth and differentiation were inhibited by mAb 5B4 (Fig. 7, C and D, respectively). Consistently, when MSC were incubated with mAb R3, which impairs u-PA/u-PAR interaction by masking the receptor, spontaneous invasion and uPA-dependent chemoinvasion, proliferation, and differentiation were inhibited (Fig. 7, A to D). Both 5B4 and $\mathrm{R} 3 \mathrm{mAb}$, at the inhibiting concentrations, had no effect on the vitality of untreated control cells, as revealed by the Trypan blue exclusion test. As previously reported for other cell lines (Fibbi et al, 1998, 1999; Quattrone et al, 1995), u-PAR expression was inhibited by treating MSC with aODN anti-u-PAR mRNA, as described above. After aODN treatment, normal and DMD MSC lost the ability to spontaneously and chemotactically invade Matrigel-coated filters, as well as their capability to proliferate and differentiate under u-PA challenge, whereas SODN showed only a limited efficacy (Fig. 7, A to D).

\section{Discussion}

The u-PA/u-PAR system has recently been studied as one of the many factors involved in muscle development, and a membrane-associated and soluble plasminogen activation system in human and murine myogenic cells has been related to muscle differentiation (Munoz-Canoves et al, 1997; Quax et al, 1992; Wells and Strickland, 1997). In this study we demonstrate that normal and DMD myoblasts differentially express u-PA, u-PAR, and PAI-I and that u-PA/u-PAR interaction stimulates invasion, proliferation, and differentiation in MSC from both sources. During the proliferation phase, before the fusion-differentiation process, normal MSC produce higher amounts of u-PA than DMD MSC, whereas expression of U-PAR and PAI-I is much higher in DMD myoblasts. Moreover, in the proliferation phase u-PAR-bound u-PA is undetectable on the surface of DMD myoblasts. Within the frame of this u-PA/u-PAR/PAI-1 pattern, normal myoblasts are more prone to spontaneous invasion than DMD myoblasts, which on the other hand are better able to sense u-PA gradients in chemoinvasion experiments. A likely explanation for the behavior of DMD MSC may rely on the balance between low u-PA and high PAl-1 production: regardless of the high number of $U$-PA receptors, the degradative machinery of DMD MSC is blocked by the absence of u-PAR-bound $\mathrm{u}-\mathrm{PA}$ and by the prevalence of the inhibitor on the activator. The opposite considerations are likely in the case of normal MSC, in which the degradative properties of u-PA overcome PAl-1 inhibition (as shown by the fibrinolytic activity of the proliferation phase reported in Figure 2A) and u-PA results bound to the receptor. Of course, in the presence of a u-PA gradient, DMD myoblasts sense the ligand better than normal MSC due to the presence of a higher number of free u-PA receptors. Noteworthy, u-PA production ceases when normal MSC reach differentiation and form myotubes. In DMD myoblasts, myotube formation is scarce and morphologically altered and u-PA continues to increase even in the last phase of cell culture. This observation is in agreement with the reported requirement of $\mathrm{u}-\mathrm{PA}$ in the predifferentiation phase of myoblasts, preparing the cells for myotube formation (Munoz-Canoves et al, 1997; Quax et al, 1992; Wells and Strickland, 1997). The binding of u-PA with $u-P A R$ has at least two major consequences: (a) the concentration of u-PA activity on the cell surface and (b) an increase in the rate of plasminogen activation occurring on the cell-associated PLG/PL binding sites, therefore optimizing the rapid generation of $\mathrm{PL}$ at the leading edge of invasive cells and activation of latent MMP. MMP are normally secreted in latent form also by myoblasts (Guerin and Holland, 1995). The mechanism of MMP activation (including their 


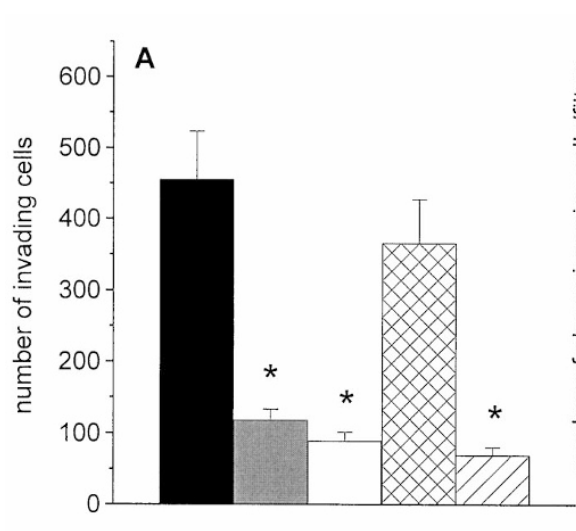

spontaneous invasion
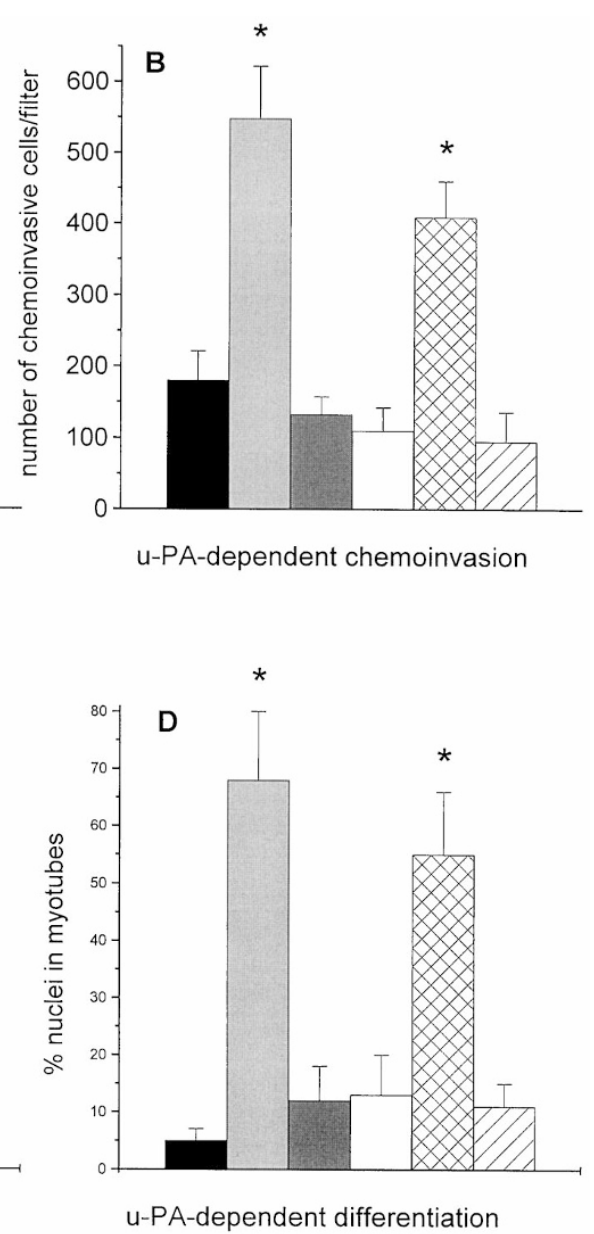

Figure 7.

Requirements of u-PA/u-PAR interaction in spontaneous invasion, u-PA-dependent chemoinvasion, and u-PA-dependent proliferation and differentiation in normal and DMD myoblasts. Data reported in this figure are the results of experiments performed in the cell line (normal or DMD) exhibiting the maximal response in each condition. It is noteworthy that similar results were always obtained for both counterparts (normal and DMD) from each of the patients examined. A, Spontaneous invasion of normal MSC under basal conditions (black), and in the presence of anti-u-PA 5B4 mAb (dark grey), anti-u-PAR R3 mAb (white), s0DN (cross-hatched), and anti-u-PAR aODN (oblique lines). Values are expressed as the number of invading cells/filter. B, u-PA-dependent chemoinvasion of DMD myoblasts under basal conditions (black), under stimulation with $100 \mathrm{ng} / \mathrm{ml} \mathrm{u-PA} \mathrm{(light} \mathrm{grey),} \mathrm{and} \mathrm{under} \mathrm{stimulation} \mathrm{with} \mathrm{u-PA} \mathrm{in} \mathrm{the} \mathrm{presence} \mathrm{of} \mathrm{mAb} \mathrm{5B4} \mathrm{(dark} \mathrm{grey),} \mathrm{mAb} \mathrm{R3} \mathrm{(white),}$ SODN (cross-hatched), aODN (oblique lines). Values represent the number of invading cells/filter. C, Proliferation of normal myoblasts under basal conditions and in the same conditions reported in panel B. Column labels are the same as in B. Values are expressed as the percentage increase or decrease of proliferation under basal conditions (as 100\%). D, Differentiation of normal MSC with $2 \mathrm{ng} / \mathrm{ml}$ exogenous u-PA, added after the beginning of the culture. The medium was changed twice a week, as described. The values shown refer to the percentage of nuclei within myotubes at Day 14 after u-PA challenge. Column labels are the same as in B. Data reported in each section represent the mean \pm SD of two different experiments performed in triplicate on two cell lines. * Indicates that values are significantly different from the corresponding value of cells under basal conditions (black column in each section) $(p<0.05)$

membrane-associated form: MT-MMP) has been studied in detail in various cell types and in different pathological settings, such as metastatic tumor spreading and angiogenesis (Andreasen et al, 1997; Bouck et al, 1996), and always a proteolytic activation cascade initiated by u-PAR-bound u-PA has been shown to be involved. Guerin and Holland (1995) have shown that MSC activate the $72 \mathrm{kDa}$ progelatinase in a PLG-dependent fashion. The functional implication of the presence of such a cell-associated proteolytic cascade in MSC is of particular interest in view of the possibility that skeletal myoblasts migrate across the basal lamina of myofibers during normal muscle development (Hughes and Blau, 1990). In fact, MSC in one muscle fiber could contribute to myogenesis or repair of distant damaged fibers. Additionally, the production of membrane-associated serine protein- ases and MMP could be of critical importance in experiments where skeletal muscle myoblasts transplanted into skeletal muscle show that they are able to pass through a native basal lamina and to fuse into preexisting muscle fibers (Hughes and Blau, 1990; Karpati et al, 1993; Morgan and Partridge, 1992; Morgan et al, 1993; Naffakh et al, 1993; Partridge et al, 1989; Tremblay et al, 1993). In this context it is important to underline that incorporation of exogenous myoblast into adult muscle is more difficult than into immature muscle, probably due to a more established and structurally organized basal membrane, thereby rendering highly inefficient exogenous myoblast reconstitution of adult muscle.

Thus far, the plasminogen activator/PL system has been envisioned as an ECM-degradative machinery, aspecifically shared by many cell types to direct cell 
invasion. In the context of muscle dynamics, this mechanism could be regarded as a complementary feature triggered by multiple factors regulating the tremendous complexity of muscle development. Herein we show that the formation of a complex between u-PA and its receptor, in addition to enhancing ECM degradation and therefore ECM invasion, is also able to directly elicit myoblast growth and differentiation.

The present observations and previous results obtained in other laboratories on the MSC-associated fibrinolytic system suggest multiple functions of the u-PA/u-PAR complex on the surface of normal and DMD MSC. (1) u-PA is produced in large amounts in the predifferentiation phase of MSC development (Munoz-Canoves et al, 1997; Quax et al, 1992; Wells and Strickland, 1997) and, after interaction with $\mathrm{u}-\mathrm{PAR}$, is an important cofactor in myotube formation after MSC alignment. (2) u-PA/u-PAR interaction drives MSC invasion and stimulates their proliferation. (3) U-PAR is mechanically coupled to the cytoskeleton and mediates mechanical force transfer across the cell surface, and u-PA/u-PAR interaction reduces myoblast stiffness, thereby favoring cell motility (Wang et al, 1995). Because it is now well established that u-PAR domains other than the u-PA-binding one interact with ECM molecules, it is likely that u-PAR provides a linkage between ECM and MSC cytoskeleton.

Although Duchenne muscular dystrophy is a disease characterized by the absence of dystrophin in the membrane-associated cytoskeleton of muscle fibers (Hoffman et al, 1987), it is well documented that myoblasts do not produce dystrophin (Lev et al, 1987). Thus the DMD and normal MSC are biochemically identical with regard to the primary genetic defect (dystrophin deficiency) through much of their differentiation program (pre-myotube). Consequently, the differential expression of the plasminogen activation system that we have observed in normal and DMD MSC from the beginning of proliferation to the alignment phase cannot be dependent on dystrophin expression. It is possible that there are microenvironmental features of dystrophic muscle that are responsible for instigating different biochemical programs in the myoblasts, which are not directly dependent on production of dystrophin. Hodges et al (1997) have shown an increase of $\alpha 7 \beta 1$ integrin, which is a major receptor for the basement membrane laminin, on the surface of skeletal myoblasts in patients with DMD and in $m d x$ mice that lack dystrophin. In these examples, a deficiency in dystrophin-mediated transmembrane linkage is accompanied by an increase in the integrin-mediated linkage of fibers and extracellular matrix. This increase in the $\alpha 7 \beta 1$ laminin receptor may compensate for the stability normally provided through the interactions of the dystrophin complex with laminin. In another experimental setting, Wang et al (1998) have shown a posttranscriptional regulation of u-PAR mRNA levels by leukocyte integrin (LFA-1) engagement, obtained through a stabilization of u-PAR mRNA controlled by $3^{\prime}$ AU-rich elements.
Therefore, since both leukocyte integrin LFA-1 and MSC integrin $\alpha 7 \beta 1$ are adhesion receptors, it is possible to speculate that overexpression of $u$-PAR in DMD MSC may be controlled by integrin $\alpha 7 \beta 1$ engagement by laminin.

The hierarchy of importance of the myoblast plasminogen activation system in muscle development is far from being elucidated, but evidence obtained in our laboratory on other cell lines indicates that some growth factors (b-FGF, PDGF) stimulate chemotaxis, chemoinvasion, and proliferation of hepatic stellate cells only in the presence of an intact cell-associated fibrinolytic system, whose inhibition abrogates every activity of such growth factors on hepatic stellate cells (Fibbi et al, 1999). If the need for an efficient fibrinolytic system proves to be true for the activity of myoblastdirected growth factors, then the forced expression of u-PA within the damaged muscle may have the additional chance to favor the activity of locally produced growth factors on resident or transplanted MSC.

\section{Materials and Methods}

\section{Antibodies and Reagents}

Monoclonal mouse anti-u-PAR antibody R3 was purchased from American Diagnostica (Montreal, Quebec, Canada). Monoclonal antibody 5B4, which recognizes the kringle domain of the $A$ chain of u-PA, previously used in other studies from this laboratory (Fibbi et al, 1998), was a kind gift of Dr. M. L. Nolli (Lepetit Research Center, Varese, Italy), as well as low molecular weight $u-P A$, the form of u-PA lacking the A chain. u-PA was obtained from Serono (Rome, Italy), and b-FGF was purchased from Amgen Biologicals (Thousand Oaks, California). Anti-desmin monoclonal antibody was purchased from Boehringer-Mannheim (Mannheim, Germany). The amino-terminal fragment of u-PA (ATF) was graciously provided by Dr. J. Henkin (Abbott Laboratories, Chicago, Illinois). Reagents for mRNA studies were from Promega (Madison, Wisconsin). Antisense-ODN for u-PAR receptor mRNA was synthesized by ISIS (San Diego, California). Phospholipase $\mathrm{C}$ specific for glycosyl phosphatidyl inositol (GPI-PLC) from Bacillus cereus, fibronectin, and other reagents for cell culture, including FCS were purchased from Sigma Chemical (St. Louis, Missouri). Diff-Quick was from Mertz-Dade AG (Dade International, Milan, Italy). Matrigel was obtained from Becton-Dickinson (Bedford, Massachusetts).

\section{Preparation and Characterization of Human MSC: Evaluation of Differentiation}

MSC were prepared and cultured according to a previously described method (Blau and Webster, 1981). Muscle biopsies obtained from the quadriceps femoris during orthopaedic surgery of six normal patients (1-3 years old) and from the quadriceps femoris of six dystrophic patients (1-6 years old, all exhibiting the absence of dystrophin, due to deletions of sequences enframed between exon 6 and 44) were digested in $0.15 \%$ pronase in PBS for 1 hour at $37^{\circ} \mathrm{C}$. 
Collagenase was not used to avoid ECM dissociation and to minimize fibroblast contamination (VerdiereSahuque et al, 1996). After centrifugation and washing, the cell population was enriched for muscle cells by preplating the cells at $37^{\circ} \mathrm{C}$ for 20 minutes on a collagen-coated dish, a substrate to which fibroblasts preferentially adhere. Nonadherent cells were collected and seeded at $6 \times 10^{4}$ cells $/ 25 \mathrm{~cm}^{2}$ flask in DMEM containing 20\% FCS, 2 mM glutamine, 100 $\mathrm{U} / \mathrm{ml}$ penicillin, and $100 \mu \mathrm{g} / \mathrm{ml}$ streptomycin. The culture media were changed every 4 days. For the experiments, cultures between second and fourth passage were used. The degree of purity of the culture and the extent of contamination by nonmyogenic cells was estimated on 8-day cultures by assaying the presence of desmin, a specific marker of the predifferentiated myoblasts and myofibroblasts, using a standard immunoperoxidase procedure with a commercial monoclonal antibody (Boehringer-Mannheim) (Mohun, 1992). In all cultures at least $90 \%$ of the cells stained positively for desmin (not shown). After plating, all the cell lines used in the study were grown in DMEM supplemented with $20 \%$ FCS (growth medium). Once confluence was reached, the cells lined up and began to fuse to form myotubes. To further promote fusion, cells were cultured in the presence of DMEM supplemented with 5\% FCS (fusion medium), as reported (Guerin and Holland, 1995). To evaluate MSC differentiation, myotube formation was determined by fixing cells in methanol, staining with DiffQuick, and quantifying the percentage of nuclei contained within multinucleated myotubes; at least 1000 myotubes were counted for each determination (Verdiere-Sahuque et al, 1996).

\section{Zymography of Released Plasminogen Activators}

Aliquots of culture medium were subjected to sodium dodecyl sulfate-polyacrylamide slab gel electrophoresis (10\%) under nonreducing conditions, and migrated proteins were transferred onto $0.45 \mu \mathrm{m}$ pore-size nitrocellulose filter (BioRad, Richmond, California) in a $0.04 \mathrm{~mol} / \mathrm{l}$ phosphate buffer (pH 6.5), under a current of 0.6 A during a 1.5-hour run. The nitrocellulose filter was removed and placed on an indicating layer containing casein and PLG, as previously described (Fibbi et al, 1999). After 10 hours of incubation at $37^{\circ} \mathrm{C}$, when clear bands of lysis were visible in the cloudy casein background, corresponding to the position of plasminogen activators in the polyacrylamide gel, zymograms were dried and stained with Ponceau $S$ solution (Sigma). u-PA activity was measured by densitometric scanning of the zymograms, against standard u-PA.

\section{Iodination of u-PA, Radioligand Binding Assay, and Enzyme-Linked Immunosorbent Assays}

lodination of the two-chain high molecular weight $\mathrm{u}-\mathrm{PA}$ and radioligand binding were performed as previously described (Fibbi et al, 1999). The specific activity of the preparation used in this study was 20.2 $\mu \mathrm{Ci} / \mu \mathrm{g} \mathrm{u}-\mathrm{PA}$. The Scatchard analysis of binding data was used to calculate the receptor number and the Kd of receptor/ligand interaction. IMUBIND total u-PAR ELISA Kit (American Diagnostica) was also used to measure u-PAR number. In this case cell monolayers were lysed with lysis buffer, as suggested by the manufacturer, and an aliquot of the cell lysate was used for $u$-PAR determination. u-PA was quantified by ELISA reagent (American Diagnostica). PAl-1 was measured by the Fl-1 PAl-1 ELISA Kit (Monozyme, Hørsholm, Denmark). The inactivation of u-PA with DFP was performed as previously described (Fibbi et al, 1988).

\section{Migration Assays}

The Boyden chamber was used to evaluate cell migration, as previously described (Fibbi et al, 1998). Two different kinds of MSC migrations were evaluated: spontaneous invasion and stimulated invasion (chemoinvasion). The method is based on the passage of cells across porous filters separating the upper and lower wells of the migration chamber. For human MSC we used polyvinyl-pyrrolidone-free polycarbonate filters, $8 \mu \mathrm{m}$ pore size. The filter was coated with the reconstituted basement membrane Matrigel $(50 \mu \mathrm{g} /$ filter; Becton Dickinson). For spontaneous invasion, $2.5 \times 10^{4}$ cells were placed in the upper compartment of the Boyden chamber and migration was allowed to occur for 6 hours at $37^{\circ} \mathrm{C}$. For chemoinvasion, test solutions were dissolved in serum-free medium and placed in the lower wells. The u-PA concentrations added to the lower well in the chemoinvasion experiments were $5,10,20,30,50,100,200,500$, and 1000 $\mathrm{ng} / \mathrm{ml}$. Fifty microliters of cell suspension $\left(2.5 \times 10^{4}\right.$ cells) were added to the upper well. In the experiments with neutralizing antibodies, the anti-u-PA mAb was put in the lower well with the test substance (u-PA, ATF), whereas anti-u-PAR mAb was incubated with the cell suspension. The chamber was incubated at $37^{\circ} \mathrm{C}$ for 6 hours and the filter was removed and fixed in methanol. Nonmigrating cells on the upper surface of the filter were removed with a cotton swab; migrated cells, adherent on the lower filter surface, were stained and counted by a light microscope (40× in 10 random fields) in each well. Mobilization was measured by the number of cells moving across the filter. Each experimental point was performed in triplicate. Mean values of migrated cells for each point were calculated. Migration was expressed as mean \pm SEM of the number of total cells counted per well or as the percentage of basal response.

\section{Proliferation Studies}

Cell growth was quantified in subconfluent cell monolayers, as previously described (Fibbi et al, 1998, 1999). MSC were seeded onto 24-well plates (Sarstedt, Verona, Italy; $15 \times 10^{3}$ cells/well) in medium supplemented with $10 \%$ FCS and were left to adhere overnight. Cells were then extensively washed in PBS and maintained for 24 hours in serum-free DMEM. 
Medium was removed and cells were incubated with serum-free medium containing increasing concentrations of u-PA (from 1 to $1500 \mathrm{ng} / \mathrm{ml}$ ) for 24 hours. As a reference for optimal growth condition, the proliferative effect of $20 \%$ FCS and of $10 \mathrm{ng} / \mathrm{ml} \mathrm{b}-\mathrm{FGF}$ was measured. In the experiments in which the neutralizing monoclonal antibodies (mAb) were used, cells were incubated 10 minutes with mAb $(1.5 \mu \mathrm{g} / \mathrm{ml})$ and then exposed to u-PA. Each experimental point was performed in triplicate. At the end of the incubation, cells were fixed by adding $1 \mathrm{ml}$ of ice-cold methanol and then stained with Diff-Quick. Cell numbers were obtained by counting by microscopic examination at 10 $\times$ magnification with the aid of an ocular grid (21 $\mathrm{mm}^{2}$ ). Each well was divided into 10 fields and the cells were counted by a double-blind procedure in seven randomly selected fields. Values are expressed as the percentage increase over basal response. Data related to the effects of $\mathrm{mAb}$ are expressed as $a$ percentage of basal control (obtained with mAb alone).

\section{Detection of u-PAR Transcripts by Quantitative RT-PCR}

cDNA synthesis was performed with $1 \mu \mathrm{g}$ of mRNA in $25 \mu$ final volume containing $50 \mathrm{~mm}$ Tris- $\mathrm{HCl}, \mathrm{pH} 8.3$, $75 \mathrm{~mm} \mathrm{KCl}, 3$ mм MgCl 2 , 10 mm DTT, 2 mм dNTPs, 0.5 $\mu \mathrm{g}$ random hexamer oligonucleotides (Promega). Samples were heated at $70^{\circ} \mathrm{C}$ for 5 minutes and rapidly chilled on ice before adding 25 units of RNAsin and 200 units of Moloney leukemia reverse transcriptase (Promega). Samples were then incubated for 1 hour at $37^{\circ} \mathrm{C}$ and heated for 10 minutes at $95^{\circ} \mathrm{C}$. Aliquots of $1 \mu$ l of cDNA mixture were serially diluted and transferred into vials for PCR amplification. PCR was performed by using either primers for u-PAR or primers for the GAPDH gene, which was used as internal standard because it is expressed at a constant per-cell level. The u-PAR gene primers were: sense 5'-GGT CAC CCG CCG CTG-3', antisense 5'-CCA CTG CGG TAC TGG ACA-3'; the u-PA gene primers were: sense 5'-AAA ATG CTG TGT GCT GCT GAC C-3', antisense 5' -CCC TGC CCT GAA GTC GTT AGT G-3'; the PAl-1 gene primers were: sense 5'-GAA CAA GGA TGA GAT CAG CAC C-3', antisense 5'-ACT ATG ACA GCT GTG GAT GAG G-3'; the GAPDH gene primers were: sense 5'-CCA CCC ATG GCA AAT TCC ATG GCA-3', antisense 5'-TCT AGA CGG CAG GTC AGG TCC ACC-3'. PCR reaction was performed in a $50 \mu$ final volume containing $5 \mathrm{~mm}$ Tris- $\mathrm{HCl}, \mathrm{pH} 8.0$, $10 \mathrm{~mm} \mathrm{NaCl}, 0.01 \mathrm{~mm}$ EDTA, $0.1 \mathrm{~mm}$ DTT, 5\% glycerol, $0.1 \%$ Triton X-100, $1.5 \mathrm{~mm} \mathrm{MgCl}_{2}$, $0.2 \mathrm{~mm}$ dNTPs, 0.5 $\mathrm{mm}$ of each primer, 1.5 units of Taq polymerase (Promega). After an initial 2-minute denaturation step at $94^{\circ} \mathrm{C}, \mathrm{PCR}$ was carried out for 35 cycles on a DNA thermocycler (MJ Research) under the following conditions: denaturation at $94^{\circ} \mathrm{C}$ for 1 minute, annealing for 1 minute at $59^{\circ} \mathrm{C}$, and an extension step for 7 minutes at $72^{\circ} \mathrm{C}$. Amplified cDNA and PCR molecular weight standards were subjected to electrophoresis on $1 \%(\mathrm{w} / \mathrm{v})$ agarose gels containing ethidium bromide
(1 $\mathrm{ng} / \mathrm{ml})$. The expected size of cDNA fragments for u-PAR was $910 \mathrm{bp}$ and for GAPDH was $598 \mathrm{bp}$.

\section{PCR Product Quantification}

The ethidium bromide-stained cDNA were photographed under an ultraviolet transilluminator by using Polaroid positive/negative instant films. Negatives of the expected size bands were quantified using a scanner (Astra 1220S, Umax Europe, Willich, Germany) equipped with a transparency option interface to an IBM-compatible computer. Negative films were scanned using the QuantiScan program developed by Biosoft (Cambridge, United Kingdom) in gray-scale mode at $600 \mathrm{dpi}$. This program integrates the density of a particular band. Values of integrated densities were plotted as a function of the increasing amount of amplified reverse transcriptase products. Within the linear range of amplification, three values of PCR products relative to $u$-PAR were normalized to the starting CDNA volumes and referred to the values of PCR products relative to the GAPDH mRNA used as internal standard. Values were reported as mean \pm SEM and were compared by Student's $t$ test.

\section{Treatment with aODN Anti-U-PAR}

To inhibit u-PAR gene expression, an 18-mer phosphorothioate aODN was used with the same sequence previously published (Quattrone et al, 1995), encompassing the translation start site of the targeted mRNA (Roldan et al, 1990). A scramble sequence 18-mer ODN (sODN) was used as negative control. ODN uptake and stability were enhanced by combining ODN $(10 \mu \mathrm{mol} / \mathrm{l})$ with a cationic liposome $(13 \mu \mathrm{mol} / \mathrm{l})$, namely DOTAP (Boehringer-Mannheim), following the procedure previously described (Quattrone et al, 1995). MSC cultures were treated with ODN for 4 days, on the basis of preliminary experiments indicating a steady-state reduction of u-PAR number after 3 days of aODN treatment. For toxicity tests, the number of living cells (Trypan blue exclusion assay) was assessed at 12-hour intervals after ODN-DOTAP addition. Apart from a transient cell shrinkage occurring in the first 12 hours after addition of the compound, the resulting cell viability was unaffected.

\section{Statistical Analysis}

Results are expressed as means $\pm \mathrm{SD}$ for $(n)$ experiments. Multiple comparisons were performed by the Student-Newman-Keuls test, after demonstration of significant differences among medians by nonparametric variance analysis according to Kruskal-Wallis.

\section{References}

Andreasen PA, Kjoller L, Christensen L, and Duffy MJ (1997). The urokinase-type plasminogen activator system in cancer metastasis: A review. Int J Cancer 72:1-22.

Blau HM and Webster C (1981). Isolation and characterization of human muscle cells. Proc Natl Acad Sci USA 78: 5623-5627. 
Bouck N, Stellmach V, and Hsu SC (1996). How tumors become angiogenic. Adv Cancer Res 69:135-174.

Campion RD (1984). The muscle satellite cells: A review. Int Rev Cytol 87:225-251.

Del Rosso M, Pedersen N, Fibbi G, Pucci M, Dini G, Anichini $E$, and Blasi $F$ (1992). Selective localization of receptors for urokinase amino-terminal fragment at substratum contact sites of an in vitro-established line of human epidermal cells. Exp Cell Res 203:427-434.

Fibbi G, Caldini R, Chevanne M, Pucci M, Schiavone N, Morbidelli L, Parenti A, Granger HJ, Del Rosso M, and Ziche M (1998). Urokinase-dependent angiogenesis in vitro and diacylglycerol production are blocked by antisense oligonucleotides against the urokinase receptor. Lab Invest 78:1109-1119.

Fibbi G, Pucci M, Grappone C, Pellegrini G, Salzano R, Casini A, Milani S, and Del Rosso M (1999). Functions of the fibrinolytic system in human Ito cells and its control by basic fibroblast and platelet-derived growth factor. Hepatology 29:868-878.

Fibbi G, Ziche M, Morbidelli L, Magnelli L, and Del Rosso M (1988). Interaction of urokinase with specific receptors stimulates mobilization of bovine adrenal capillary endothelial cells. Exp Cell Res 179:385-395.

Guerin CW and Holland PC (1995). Synthesis and secretion of matrix-degrading metalloproteases by human skeletal muscle satellite cells. Dev Dyn 202:91-99.

Hartley RS, Bandman E, and Yablonka-Reuveni Z (1991). Myoblasts from fetal and adult skeletal muscle regulate myosin expression differently. Dev Biol 148:249-260.

Hodges BL, Hayashi YK, Nonaka I, Wang W, Arahata K, and Kaufman SJ (1997). Altered expression of the $\alpha 7 \beta 1$ integrin in human and murine muscular dystrophies. J Cell Sci 110: 2873-2881.

Hoffman EP, Brown J, and Kunkel LM (1987). Dystrophin: The protein product of the Duchenne Muscular Dystrophy locus. Cell 51:919-928.

Hughes SM and Blau HM (1990). Migration of myoblasts across basal lamina during skeletal muscle development. Nature 345:350-353.

Karpati G, Ajdukovic D, Arnold D, Gledhill RB, Guttmann R, Holland P, Koch PA, Shoubridge E, Spence D, Vanasse M, Watters GV, Abrahamowicz M, Duff C, and Worton RG (1993). Myoblast transfer in Duchenne muscular dystrophy. Ann Neurol 34:8-17.

Lev AA, Feener CC, Kunkel LM, and Brown RH Jr (1987). Expression of the Duchenne's Muscular Dystrophy gene in cultured muscle cells. J Biol Chem 262:15817-15820.

Li Y, Wood N, Yellowlees D, and Donnelly PK (1999). Urokinase receptor expression is upregulated by cell culture sparsity in breast cancer cell line. Anticancer Res 19:4247-4250.

Mignatti P and Rifkin DB (1993). Biology and biochemistry of proteinases in tumor invasion. Physiol Rev 73:161-195.

Mohun T (1992). Muscle differentiation. Curr Opin Cell Biol 4:923-928.

Morgan JE, Pagel CN, Sherrat T, and Partridge TA (1993). Long-term persistence and migration of myogenic cells injected into pre-irradiated muscles of $m d x$ mice. J Neurol Sci 115:191-200.

Morgan JE and Partridge TA (1992). Cell transplantation and gene therapy in muscular dystrophy. Bioessays 14:641-645.
Moss FP and Leblond CP (1971). Satellite cells as a source of nuclei in muscle of growing rats. Anat Rec 170:421-436.

Munoz-Canoves P, Miralles F, Baiget M, and Felez J (1997). Inhibition of urokinase-type plasminogen activator (UPA) abrogates myogenesis in vitro. Thromb Haemost 77:526-534.

Naffakh N, Pinset C, Montarras D, Pastoret C, Danos O, and Heard JM (1993). Transplantation of adult-derived myoblasts in mice following gene transfer. Neuromuscul Disord 3:413-417.

Partridge TA, Morgan JE, Coulton GR, Hoffman EP, and Kunkel LM (1989). Conversion of $\mathrm{mdx}$ myofibres from dystrophin-negative to -positive by injection of normal myoblasts. Nature 337:176-179.

Plow EF, Freaney DE, Plescia J, and Miles LA (1986). The plasminogen system and the cell surfaces: Evidence for plasminogen and urokinase receptors on the same cell type. J Cell Biol 103:2411-2420.

Quattrone A, Fibbi G, Anichini E, Pucci M, Zamperini A, Capaccioli S, and Del Rosso M (1995). Reversion of the invasive phenotype of transformed human fibroblasts by anti-messenger oligonucleotide inhibition of urokinase receptor gene expression. Cancer Res 55:90-95.

Quax PHA, Frisdal E, Pedersen N, Bonavaud S, Thibert PH, Martelly I, Verhejien JH, Blasi F, and Barlovatz-Meimon G (1992). Modulation of activities and RNA level of the components of the plasminogen activation system during fusion of human myogenic satellite cells in vitro. Dev Biol 151:166-175.

Roldan AL, Cubellis MV, Masucci MT, Behrendt N, Lund LR, Dano K, and Blasi F (1990). Cloning and expression of the receptor for human urokinase plasminogen activator, a central molecule in cell-surface plasmin-dependent proteolysis. EMBO J 9:467-474.

Strittmatter WA, Couch LB, and Elias SB, editors (1982). Muscle development, molecular and cellular control. Cold Spring Harbor: Cold Spring Harbor Laboratory, 317-318.

Tremblay JP, Bouchard JP, Malouin F, Théau D, Cottrell F, Collin H, Rouche A, Gilgenkrantz S, Abbadi N, Tremblay M, Tomé FMS, and Fardeau M (1993). Myoblast transplantation between monozygotic twin girl carriers of Duchenne muscular dystrophy. Neuromuscul Disord 3:583-592.

Vassalli JD and Pepper MS (1994). Membrane proteases in focus. Nature 370:14-15.

Verdiere-Sahuque M, Akaaboune M, Lockhar S, Festoff BW, Jandrot-Perrus M, Garcia L, Barlovatz-Meimon G, and Hantai D (1996). Myoblast fusion promotes the appearance of active protease nexin 1 on human muscle cell surfaces. Exp Cell Res 222:70-76.

Wang GJ, Collinge M, Blasi F, Pardi R, and Bender JR (1998). Posttranscriptional regulation of urokinase plasminogen activator receptor messenger RNA levels by leukocyte integrin engagement. Proc Natl Acad Sci USA 95:6296-6301.

Wang N, Planus E, Pouchelet M, Fredberg JJ, and BarlovatzMeimon G (1995). Urokinase receptor mediates mechanical force transfer across the cell surface. Am J Physiol 268: C1062-C1066.

Wells JM and Strickland S (1997). Regulated localization confers multiple functions on the protease urokinase plasminogen activator. J Cell Physiol 171:217-225.

Yablonka-Reuveni Z, Quinn LS, and Nameroff M (1987). Isolation and clonal analysis of satellite cells from chicken pectoralis muscle. Dev Biol 119:252-259. 